\title{
The scent of enrichment: Exploring the effect of odour and biological salience on behaviour during enrichment of kennelled dogs
}

\author{
Katie Murtagh ${ }^{\mathrm{a}}$, Mark J. Farnworth ${ }^{\mathrm{a}, \mathrm{b}}$, Ben O. Brilot ${ }^{\mathrm{a}, \mathrm{c}, *}$ \\ ${ }^{a}$ School of Biological and Marine Sciences, University of Plymouth, Drake Circus, Plymouth, PL4 8AA, United Kingdom \\ ${ }^{\mathrm{b}}$ School of Animal, Rural and Environmental Sciences, Nottingham Trent University, Brackenhurst Campus, Southwell, Nottinghamshire, NG25 0QF, United Kingdom \\ ${ }^{\mathrm{c}}$ Department of Animal and Agriculture, Hartpury University, Gloucester, GL19 3BE, United Kingdom
}

\section{A R T I C L E I N F O}

\section{Keywords:}

Dog

Enrichment

Olfaction

Shelter

Toy

Welfare

\begin{abstract}
A B S T R A C T
Worldwide, millions of dogs are held in kennels for extended periods of time and may experience compromised welfare. Enrichment, often using toys, is considered important to minimize the negative impacts of kennelling. However, the value of this enrichment may be based on various sensory facets of such toys and untangling the relative contributions is a residual challenge. Therefore, improving the utility of toys as enrichment is contingent on an improved understanding of the relationship between the properties of a toy and a dog's interaction with it. The present study aimed to evaluate the addition of two different scents to toys, both presumed to have a different level of biological salience. The behaviour and level of toy engagement of 44 singly housed dogs in a rehoming centre was compared amongst no-toy (NT), unscented-toy $(\mathrm{T})$ and scented-toy $(\mathrm{T}+)$ treatments. For $\mathrm{T}+$ two scents were used: rabbit $(\mathrm{T}+\mathrm{R})$ and lavender $(\mathrm{T}+\mathrm{L})$. Toys were colour and type-matched for each treatment. Many of the datasets were zero-inflated therefore a Hurdle analysis was used to explore the relationships amongst the treatments. Non-zero inflated behavioural data were analysed using a Linear Mixed Model to discern treatment effect. Dogs were significantly more likely to interact, and interacted for longer, with scented toys. This was both in comparison to periods when only unscented toys were present and when both scented and unscented toys were simultaneously presented. However, there was no difference in response to the rabbit or lavender scented toys. Provision of scent also significantly reduced stress related behaviours and increased exploration. However, alterations in behaviour were not directly related to likelihood or amount of toy use, suggesting the scents were altering behaviour through means other than increasing physical enrichment use. These findings suggest that augmentation of toys using scents may improve engagement of dogs with them, and positively affect behavioural welfare indicators in the kennelled environment. The use of novel scents may therefore promote better welfare in kennels irrespective of their presumed biological salience, but differing scents should be further trialled.
\end{abstract}

\section{Introduction}

Globally, the annual number of dogs entering shelters is likely to be vast, e.g. within the United Kingdom (UK) the number exceeds 89,000 (Stavisky et al., 2012). The majority of dogs entering kennels are likely to exhibit signs of distress at some point during the process (Hennessy et al., 1997; Part et al., 2014; Rooney et al., 2007). Sources of stress range from confinement in limited spaces; lack of complexity in kennel housing; the continuing (though changing) practice of single-housing of a social animal; limited human contact, especially in the most beneficial manner of prolonged petting contact; and overstimulation, particularly in relation to dangerously loud levels of barking induced in a kennel environment (Taylor and Mills, 2007). The lack of control and predictability for dogs in this environment are considered to be prime sources of stress (Taylor and Mills, 2007), and are generally major factors underpinning stress (Koolhaas et al., 2011). Continuing stress, and the associated behaviours, may decrease the likelihood of adoption and increase time at shelter, based on public perception of dogs favourable for adoption being calm but interactive (Protopopova and Wynne, 2014; Wells and Hepper, 1992). This has significant implications for the long-term welfare of kennel-housed dogs.

One means of reducing undesirable impacts of the kennelled environment might be to provide enrichment. However, reports concerning enrichment for kennelled dogs are equivocal. In-kennel training sessions of 20-45 min per dog have been shown to decrease the magnitude of negative behavioural change, such as increased jumping

\footnotetext{
* Corresponding author at: Department of Animal and Agriculture, Hartpury University, Gloucester, GL19 3BE, United Kingdom.

E-mail address: ben.brilot@hartpury.ac.uk (B.O. Brilot).
} 
and barking (Hennessy et al., 2002; Coppola et al., 2006; Herron et al., 2014). Studies of shorter sessions of human interaction ( $2 \mathrm{~min}$ daily) were found to have no significant effect on stress (Conley et al., 2014). Dogs walked for fifteen minutes one day a week were more likely to stand at the front of the kennel and wag their tails in response to people, however no clear effect was found on welfare measures (Normando et al., 2009). Many centres are full (Stavisky et al., 2012) meaning staff may not have opportunity to apply time-consuming enrichment techniques for each dog. As a result, some kennels may opt to put dogs in pens to exercise alone (Association of Dogs and Cats Homes (ADCH), 2015; Royal Society for the Prevention of Cruelty to Animals (RSPCA), 2015). Unfortunately, a study by Cafazzo et al. (2014) found that whilst being taken for a walk had a positive impact on welfare, time in a pen did not.

Many rescue centres use toys and chews (a subset of toys designed specifically to be chewed) as a quick, easily implemented, enrichment strategy (ADCH, 2015; RSPCA, 2015). The evidence for their efficacy is, however, mixed (e.g. see Wells, 2004b). Some studies have demonstrated small, but measurable, positive behavioural influences of a range of toys (e.g. increasing activity levels) (Wells, 2004a). But the most convincing studies have found evidence in laboratory-housed dogs rather than rescue shelter dogs, potentially due to the relatively low frequency of stimulation in the former versus the latter (Wells, 2004b; Hubrecht, 1993). More commonly, dogs seem to prefer food-based enrichment to toys (Döring et al., 2016a). In addition, chews and toys have been known to cause injury, cannot be used for group-housed dogs due to resource guarding and do not engage all individuals (Döring et al., 2016b; Schipper et al., 2008). When non-food related toys have been used the majority of dogs do not interact with them (Wells and Hepper, 1992) and those that do spend relatively little time doing so (Pullen et al., 2010; Wells and Hepper, 2000), nor do they have a significant impact on behaviour (Wells, 2004b; Wells and Hepper, 2000). Therefore, it appears that motivation for toy-use is low, potentially in part because toys do not adequately mimic the multi-component stimuli of naturally arousing objects.

Domestic dogs have a highly developed sense of smell (Goodwin et al., 2010; Cornu et al., 2011) and may, therefore, benefit from olfactory stimulation. Olfactory enrichment in canids has, historically, received little attention. Dogs have been shown to respond to diffused essential oils (Graham et al., 2005b) where lavender caused dogs to spend more time resting and less time vocalizing whilst rosemary and peppermint resulted in more movement and vocalization. Similarly, research using a limited sample of dogs, suggested that the provision of plant-based compounds may be successful in reducing negative behaviours (i.e. vocalization) and overall activity (vanilla, valerian, coconut and ginger) whilst promoting sleep (coconut and ginger; Binks et al., 2018). Olfaction-based products, specifically designed to promote behavioural change in dogs (i.e. Dog-Appeasing Pheromone (DAP)), have been shown to have relatively little impact in shelters (Hermiston et al., 2018). Therefore, further study of olfactory enrichment to improve the welfare of kennelled dogs seems fertile ground, especially if considering other non-plant-based scents which may have greater biological relevance (e.g. those associated with prey species). For example, placing Grant's gazelle (Gazella granti) dung outside African wild dogs' (Lycanon pictus) enclosure led to more activity and pro-social behaviour. Scented items and herb water had other effects, increasing activity levels and scanning and sniffing behaviour but not reducing abnormal behaviours (Price, 2010). The addition of cat urine to a toy cat did not increase the dogs' interest as compared to an unscented version but did increase sniffing of a pillow which had previously elicited less interest than the toy (Hoffman et al., 2017). This suggests scent can add salience to items that dogs might otherwise have little motivation to interact with.

Previous studies have looked at scent enrichment or scent-enriched object effects on behaviour/welfare in kennel-housed dogs (e.g. Binks et al., 2018; Graham et al. 2005) but the present study is the first study designed to assess the impact of scent as a component of toy-based enrichment for kennelled dogs. It was hypothesised that enrichment with toys would have a positive behavioural impact. Furthermore, it was considered that scents applied to the toys (lavender and rabbit), with the latter having the potential to be more biologically salient, would have an additional and beneficial effect.

\section{Materials and methods}

\subsection{Subjects}

The study used 44 kennelled dogs that had been relinquished to Dogs Trust Darlington (UK) rehoming centre from October to February 2015-16. All subjects had been at the rehoming centre for at least seven days (median: 2.5 weeks, range: 7 days-5 years) and individually housed (on the recommendation of the centre's behaviourist) and in their current kennel for $24 \mathrm{~h}$. Individuals were all older than one year (modal age range 2-5 years), considered to be in good health and had been neutered. Where the age of the dog was unknown, a veterinarian provided an estimated range. Of the sample, 26/44 were male and the majority of dogs (32/44) were crossbreeds.

\subsection{Daily husbandry}

Dogs were housed in parasol-style kennel blocks (i.e. with individual kennels radiating out from a central service area) with separate indoor $\left(3.7 \mathrm{~m}^{2}\right)$ and outdoor $\left(5.9 \mathrm{~m}^{2}\right)$ areas. The kennels were furnished with blankets, dog beds and a variety of toys. Dogs were fed at $0800 \mathrm{~h}$ and $1630 \mathrm{~h}$. Kennels were cleaned between $0830 \mathrm{~h}$ and $1100 \mathrm{~h}$, following which dogs were taken for a short walk or placed in a grass run. All trials were carried out after cleaning and before the dog had been exercised.

\subsection{Procedure}

Scents were added to standard toys and the dogs' interactions compared to unscented versions. Data were also collected in the absence of any toys. Rabbit (Oryctolagus cuniculus) and French lavender (Lavandula stoechas) scents were selected due to them being safe for use with dogs, easy to acquire and low cost.

Each dog took part in three treatments on the same day, with a break of at least $10 \mathrm{~min}$ between them. Each treatment lasted for $20 \mathrm{~min}$ and the order was counterbalanced to avoid order effects. All trials were carried out on a Wednesday when the centre was closed to the public. Staff were instructed not to enter or walk directly past the kennel during a trial, but were still active generally around the site. The experimenter was also out-of-view during trials, after setting up the camera and placing the toys. Dogs were restricted to the outside area of their kennel during test sessions, and confined to the inside area during changes of treatment. Confining the dogs for short periods in this way is in line with other standard husbandry procedures at the centre (e.g. cleaning).

The three experimental periods were: 1 . 'no toys' (NT), all toys (if any were present) were removed leaving no toys in the kennel; 2. 'unscented toys' (T), three differently coloured, unscented toys placed in the kennel; and 3. experimental 'scented toys' $(\mathrm{T}+)$, three toys identical to those in $\mathrm{T}$ of which two were additionally scented and placed in the kennel. For $\mathrm{T}+10 \mathrm{ml}$ of lavender oil (Spa Of The World ${ }^{\mathrm{TM}}$ French Lavender Oil) was added to an orange-white toy $(\mathrm{T}+\mathrm{L})$ and $10 \mathrm{ml}$ rabbit gland and pelt scent (National Scent Company) to a redblue toy $(T+R)$, a blue-black toy was left unscented. Each scent was always on the same colour for identification. The use of identical colours in $\mathrm{T}+$ and $\mathrm{T}$ allowed any colour preference shown in the $\mathrm{T}$ condition to be noted and subsequently separated from any scent preference shown in $\mathrm{T}+$. Toys were placed in the centre of the kennel. The order of the toys (left to right) was counterbalanced between subjects to avoid side bias but was equivalent in the $\mathrm{T}$ and 
$\mathrm{T}+$ condition for each subject. Toys were handled with disposable gloves and stored in zip-lock freezer bags to prevent contamination. Toys were sterilized (soaked in Milton ${ }^{\circledast}$ and machine washed at $60 \mathrm{C}^{\circ}$ ) between uses. Worn toys were thrown away and replaced as needed. The toys used were knotted ropes (Dogloveit Cotton 3-Knot Braided Rope); past history of the dogs with the same toys was unknown. However, most dogs had been exposed to similar toys during their time at the centre therefore, due to habituation, rates of interaction are likely to be lower than on initial toy introduction. In line with other experiments on scent enrichment (e.g. Binks et al., 2018; Graham et al. 2005), it was not feasible to isolate non-focal animals from experimental scents, therefore we cannot guarantee that all subjects perceived all scents as novel. However, our results are intended for application in this real-world context, wherein dogs can be expected to have had a range of previous scent and toy experiences. Most importantly, we were concerned with the impact of the physical combination of the two components (toy and smell), rather than an inherent response to either.

\subsection{Data collection}

Video cameras (GoPro Hero4 Silver) were set up on a mount at approximately $1 \mathrm{~m}$ from the dog's kennel whilst they were shut inside. Behaviour scoring began as soon as the dog moved into the outside area. Behaviours associated with positive and negative affective states in individually housed dogs were identified via literature review and compiled into ethograms (Tables 1 and 2). Behaviours identified in the literature were discarded if they were social or the literature was equivocal. State behaviour durations (Table 1) were recorded continuously and event behaviours (Table 2) as a frequency. As vocalization could co-occur with any other behaviour it was recorded simultaneously. Likewise, when two event behaviours co-occurred both were counted. Video footage was scored using The Observer ${ }^{\circledR}$ XT version 13 (Noldus, Wageningen, Netherlands). Due to logistics all videos were watched by a single observer who was also the experimenter. Analysis of the videos occurred sequentially. The NT recordings were able to be identified due to the absence of toys, however $\mathrm{T}$ and $\mathrm{T}+$ could not be discerned as the toys and placement of the toys were identical. Identification of the experimental period $(\mathrm{T} / \mathrm{T}+)$ was conducted after all data had been extracted from the recordings, thus avoiding unintentional observer bias.

\subsection{Statistical analysis}

To capture rare, but important, behaviours indicative of affective state the frequencies of stress-related event behaviours (Table 2) were summed for each dog and analysed as a single total. The same was done for durations relating to the state behaviours: pacing, wall bouncing, tail chasing, circling and play bouncing (Table 1) and the total analysed as duration of abnormal repetitive behaviour. All analyses were carried out using RStudio (v1.1.456) and R (v3.3.2). (R Core Team, 2016). The packages used for analyses were 'Ime4' (Bates et al., 2015) and 'ImerTest' (for LMM analysis, Kuznetsova et al., 2017) and 'psych' for correlation analyses (Revelle, 2018). The dataset and analysis code are available at https://doi.org/10.5281/zenodo.2641955.

Toy use was analysed across the $\mathrm{T}$ and $\mathrm{T}+$ periods to establish the impact of scent presence and scent type $(T+R ; T+L)$, including whether there was any prior preference for a particular colour pre scent addition, or post scent addition for a particular scent. Due to the extreme right skew in duration of toy interaction, a Hurdle type approach (i.e. a hurdle-at-zero) to analysing the data was adopted (Mullahy, 1986). Formally, this approach is applied to zero-inflated Poisson data. It assumes that two processes operate in generating the data distribution: 1. A process that explains whether a non-zero count is observed or not (i.e. 'success' vs. 'no success'); 2. A process that explains the actual magnitude of the count, given the count is at least one. This is an appropriate model here since we can assume that each dog's decision to start any kind of interaction with a toy differs from the behavioural decision to terminate that interaction. Unfortunately, the durations were not generated from a Poisson-type process so we deviate from the strict Hurdle approach by analysing the behavioural measure firstly as a binomial outcome (behaviour observed vs. not observed). Instances where none of the behaviour was observed were then excluded and the duration of behaviour analysed.

For other behavioural measures, either the above approach was taken (where extreme skew and zero-inflation occurred) or a more straightforward Linear Mixed Model (LMM) was applied. For LMMs the behavioural measure was included as the dependent variable while experimental period (NT, $\mathrm{T}, \mathrm{T}+$ ) was included as a fixed factor and dog identity was included as a random factor to control for the repeated measures. To establish whether an experimental variable has a significant effect it was removed from the analysis and then the resulting

Table 1

Ethogram of state behaviours identified through review of the literature. Behaviours identified as "not analysed" are included for completeness.

\begin{tabular}{|c|c|c|c|}
\hline Behaviour & Description & Affect & Origin* \\
\hline Alert & $\begin{array}{l}\text { Mostly still, may be sitting, standing or lying down but with head up. Eyes are open and moving, ears are forward and twitching/ } \\
\text { swivelling. }\end{array}$ & Not analysed & 1,2 \\
\hline Vigilant & Staring at point or points, legs and face tense and may be crouched, tail tucked, trembling, whale-eye, lip licking or panting. & Not analysed & N/A \\
\hline Explore & $\begin{array}{l}\text { Walks with nose close to floor sniffing, sniffs objects, moves things with paws or nose to investigate underneath (excluding toy } \\
\text { interactions). }\end{array}$ & Positive & $1,3,2$ \\
\hline Interact with toy & $\begin{array}{l}\text { Bats around toy with paws. Picks up and flings, chews, licks, shakes, sniffs or noses. Jumps or rolls on. Each toy colour/ scent } \\
\text { recorded separately. }\end{array}$ & Positive & 1,2 \\
\hline Sleep & $\begin{array}{l}\text { Lying down with head rested down, can be on side, sphinx position with hips on one side, on back, partially or fully curled. Eyes } \\
\text { are closed for more than two minutes. }\end{array}$ & Positive & 4,5 \\
\hline Rest & $\begin{array}{l}\text { Lying down on side, sphinx position with hips to one side and head down, on back, partially or fully curled. Eyes drift open and } \\
\text { closed. }\end{array}$ & Positive & $6,7,5,8$ \\
\hline Vocalization & Whining, barking, yelping, yowling or howling. & Negative & $4,2,8$ \\
\hline Pace & Paces around or across kennel in a fixed route. Pattern is repeated three or more times. & Negative & $9,10,3,2$ \\
\hline Wall bounce & $\begin{array}{l}\text { Jumps up kennel wall two or more times, may be in the same place or different (provided other behaviours don't occur aside from } \\
\text { crossing to new wall area). }\end{array}$ & Negative & $9,3,2$ \\
\hline Tail chase & Turns in a tight circle with mouth open following own tail. May chew or bite tail. & Negative & $9,3,2$ \\
\hline Circle & Walks or bounces in a tight circle (on the spot) two or more times. & Negative & $11,3,2,8$ \\
\hline Play bounce & $\begin{array}{l}\text { Similar to the play bow except chest is not so close to the floor. Front legs partially stretched out front and rump higher than head. } \\
\text { Movement is fast and jerky. }\end{array}$ & Negative & $9,10,3,2$ \\
\hline Active other & Any other active behaviour. & Not analysed & N/A \\
\hline Inactive other & Any other inactive behaviour. & Not analysed & N/A \\
\hline
\end{tabular}

* Reference(s) from which the behaviour was identified: 1: Boissy et al. (2007); 2: Kiddie and Collins (2014); 3: Hubrecht et al. (1992); 4: Hetts et al. (1992); 5: Part et al. (2014); 6: Beerda et al. (1998); 7: Owczarczak-Garstecka and Burman, (2016); 8: Walker et al. (2009); 9: Beerda et al. (1997); 10: Beerda et al. (1999); 11: Beerda et al. (2000). 
Table 2

Ethogram of event behaviours identified as associated with stress based on literature reviewed.

\begin{tabular}{|c|c|c|c|}
\hline Behaviour & Description & Affect & Origin* \\
\hline Lip or snout lick & Lip or snout licking, lip smacking, chews or swallows nothing. Do not count if has taken a drink in the last 10 seconds. & Negative & $4,5,2$ \\
\hline Yawn & Wide, slow opening of the mouth may be accompanied by an exhale or whine. & Negative & 3,5 \\
\hline Crouch & Lowered body position, legs are bent, tail is low/ tucked (where breed appropriate) and the ears are back. & Negative & $4,5,3,2$ \\
\hline Copraphagy & Eats own or others' faeces. & Negative & 5,2 \\
\hline Paw lift & Raises one of forepaws and holds it there for more than two seconds. & Negative & $4,5,6,2$ \\
\hline Startle & $\begin{array}{l}\text { Legs flex briefly. Head and/ or body move up and back in a quick brief motion and/or moves back a few paces suddenly. May be in } \\
\text { response to sudden sound or sight. }\end{array}$ & Negative & $5,6,1,2$ \\
\hline Body shake & Shakes whole body (looks like behaviour dogs use to remove water from coat). & Negative & $3,4,5,6$ \\
\hline
\end{tabular}

* Reference(s) from which the behaviour was identified: 1: Boissy et al. (2007); 2: Kiddie and Collins (2014); 3: Beerda et al. (1998); 4: Beerda et al. (1997); 5: Beerda et al. (1999); 6: Beerda et al. (2000).

model was compared to the full model in a Likelihood Ratio test (comparing the relative variance explained in each model against a chisquare distribution with appropriate degrees of freedom). Where a significant difference occurred it was probed using planned Helmert contrasts comparing the NT period with the $\mathrm{T} / \mathrm{T}+$ periods combined and then comparing solely the $\mathrm{T}+$ with $\mathrm{T}$ periods. Each behavioural measure was analysed in a separate linear model. Other approaches that might have combined these measures (e.g. MANOVA, PCA, discriminant function analysis) were not appropriate due to extreme skew and non-independence in the data structure. Assumptions were checked and transformations applied as appropriate, though the data are presented as raw outcome measures in figures for clarity. Though the experiment was fully counterbalanced, we were mindful that in some twothirds of trials the NT condition followed exposure to toys (i.e. there may have been a negative contrast effect). As such we also examined whether this factor was significant in any and all behavioural aspects (it was not, all $p>0.058)$. We also examined the sensitivity of other statistical analyses to the inclusion of this factor. Again, it did not change any of the statistical conclusions as laid out in the Results section (for analyses and figures see deposited data and code).

\subsection{Ethical considerations and approval}

The trials were designed and timed so as not to disrupt the dogs' normal routine or compromise their chances of being rehomed. The scents selected were thought to be non-aversive to dogs; however, it was planned that any dog considered to be having a negative reaction to the scented toys would be withdrawn from the study. In the event, no such aversion occurred. The methods and scents were approved by Plymouth University's animal welfare ethical review body and the veterinary and behavioural team at the rehoming centre.

\section{Results}

\subsection{Toy use}

A generalized linear mixed model (GLMM) analysis of binomial outcomes was carried out where interaction with a specific toy (Yes/ No) was the dependent variable; the independent variables were the presence of scented toys, scent type, and a presence of scent*scent type interaction. A significant effect of the presence of scents on the likelihood of dogs interacting with toys was identified $\left(\chi^{2}(3)=34.15\right.$, $\mathrm{p}<0.001$ ) (Table 3). However, there was no effect of scent identity $\left(\chi^{2}(4)=2.82, p=0.588\right)$, nor any significant interaction of period*scent $\left(\chi^{2}(2)=2.74, p=0.254\right)$. In simpler terms, having scented toys present in the kennel increased the likelihood of using both the scented and unscented toys.

Analysis of logged toy interaction duration using an LMM showed a significant effect of period $\left(\chi^{2}(3)=222.25, \mathrm{p}<0.001\right)$, scent identity $\left(\chi^{2}(4)=87.08, \mathrm{p}<0.001\right)$ and interaction between period and scent $\left(\chi^{2}(2)=52.09, \mathrm{p}<0.001\right)$ (Fig. 1). Planned Helmert contrasts of the
Table 3

Cross-tabs of one/zero on toy interaction for unscented (T) vs. scented ( + +) experiment periods.

\begin{tabular}{llll}
\hline Treatment & Toy Colour and Scent & $\begin{array}{l}\text { No toy } \\
\text { interaction }\end{array}$ & Toy interaction \\
\hline $\begin{array}{c}\text { Unscented toys } \\
\text { (T) }\end{array}$ & $\begin{array}{l}\text { Blue-Black (unscented) } \\
\text { Orange-White }\end{array}$ & 11 & 33 \\
(unscented) & 13 & 31 \\
Scented toys (T+) & Red-Blue (unscented) & 12 & 32 \\
& Blue-Black (unscented) & 4 & 40 \\
& Orange-White & 1 & 43 \\
& (Lavender) & & 42 \\
\hline
\end{tabular}

effect of control vs. scented toys and lavender vs. rabbit scented toys (combining both $\mathrm{T}$ and $\mathrm{T}+$ periods) were undertaken. A significant difference in the duration of interaction involving control vs. scented $(\mathrm{T}+\mathrm{R}, \mathrm{T}+\mathrm{L})$ toys was found $(\mathrm{t}(220)=-10.31, \mathrm{p}<0.001)$ but not between duration of interaction with $\mathrm{T}+\mathrm{L}$ vs. $\mathrm{T}+\mathrm{R}$ toys $(\mathrm{t}$ $(220)=0.50, p=0.619)$. The interaction effect was also explored using planned contrasts, the effect of $\mathrm{T}$ vs. $\mathrm{T}+$ varied according to period $(\mathrm{t}(220)=7.65, \mathrm{p}<0.001)$ but not when comparing $\mathrm{T}+\mathrm{R}$ with $\mathrm{T}+\mathrm{L}(\mathrm{t}(220)=-0.56, \mathrm{p}=0.576)$. More plainly, there was no prior difference in interaction rates between differently coloured toys, but the addition of any scent increased the duration of interaction significantly as compared to simultaneously presented unscented toys.

\subsection{Stress-related behaviours}

Experimental period significantly affected frequency of expression of stress-related event behaviours $\left(\chi^{2}(2)=73.24, p<0.001\right.$; Fig. 2). Planned contrasts revealed that there was a significant reduction in these behaviours when comparing NT to $\mathrm{T}$ and $\mathrm{T}+$ combined $(\mathrm{t}(86)=$ $-7.35, \mathrm{p}<0.001)$ and from $\mathrm{T}$ to $\mathrm{T}+$ conditions $(\mathrm{t}(86)=-7.85$, $\mathrm{p}<0.001)$.

\subsection{Abnormal repetitive behaviours}

There was a significant effect of experimental period on the likelihood or not of demonstrating at least some kind of abnormal repetitive behaviour $\left(\chi^{2}(2)=32.92, \mathrm{p}<0.001\right.$; Table 4). Planned contrasts revealed a significant difference in likelihood of performing ARBs, with them being less likely during $\mathrm{T}$ and $\mathrm{T}+$ phases $(\mathrm{z}=3.65, \mathrm{p}<0.001)$. Contrasts also showed that ARBs were less likely to be performed when interacting with $\mathrm{T}+$ toys vs. $\mathrm{T}$ toys $(\mathrm{z}=-4.57, \mathrm{p}<0.001)$. However, excluding samples where zero ARBs were demonstrated revealed no significant effect of time period on the duration of ARB performance $\left(\chi^{2}(2)=5.39, \mathrm{p}=0.0675\right.$; Fig. 3$)$. 


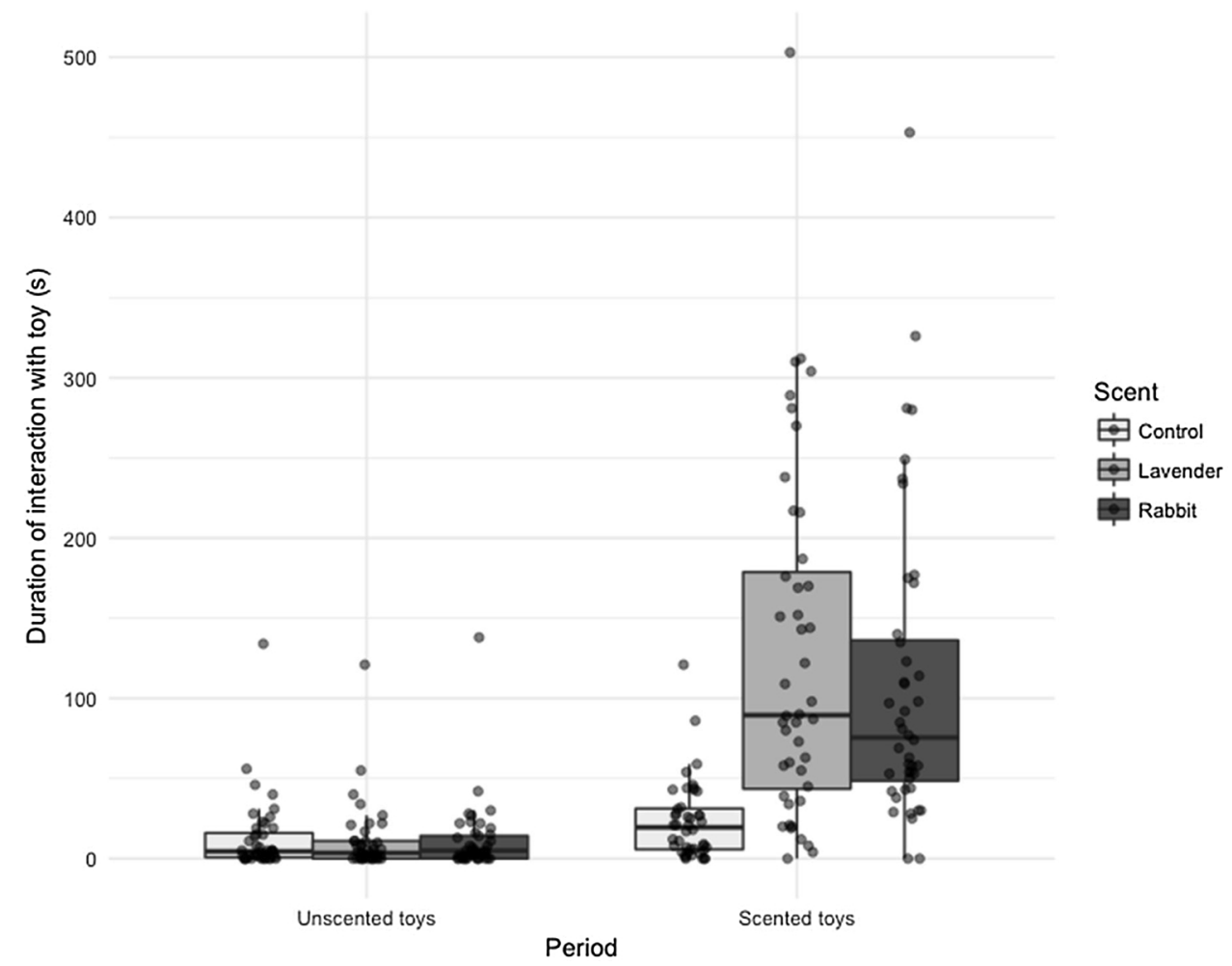

Fig. 1. Duration of interaction with toys (in seconds) across Unscented toys ( $\mathrm{T}$ ) and Scented toys $(\mathrm{T}+$ ) periods. Key shows matched identity of toys used (i.e. colours of the toys were matched from $\mathrm{T}$ to $\mathrm{T}+$ ).

\subsection{Vocalization}

There was no significant effect of experimental period on the frequency of vocalizations $\left(\chi^{2}(2)=4.62, \mathrm{p}=0.099\right)$.

\subsection{Exploration}

There was a significant effect of period on the likelihood or not of demonstrating at least some kind of exploratory behaviour $\left(\chi^{2}(2)=15.75, \mathrm{p}<0.001 ;\right.$ Table 4$)$. Planned contrasts revealed a

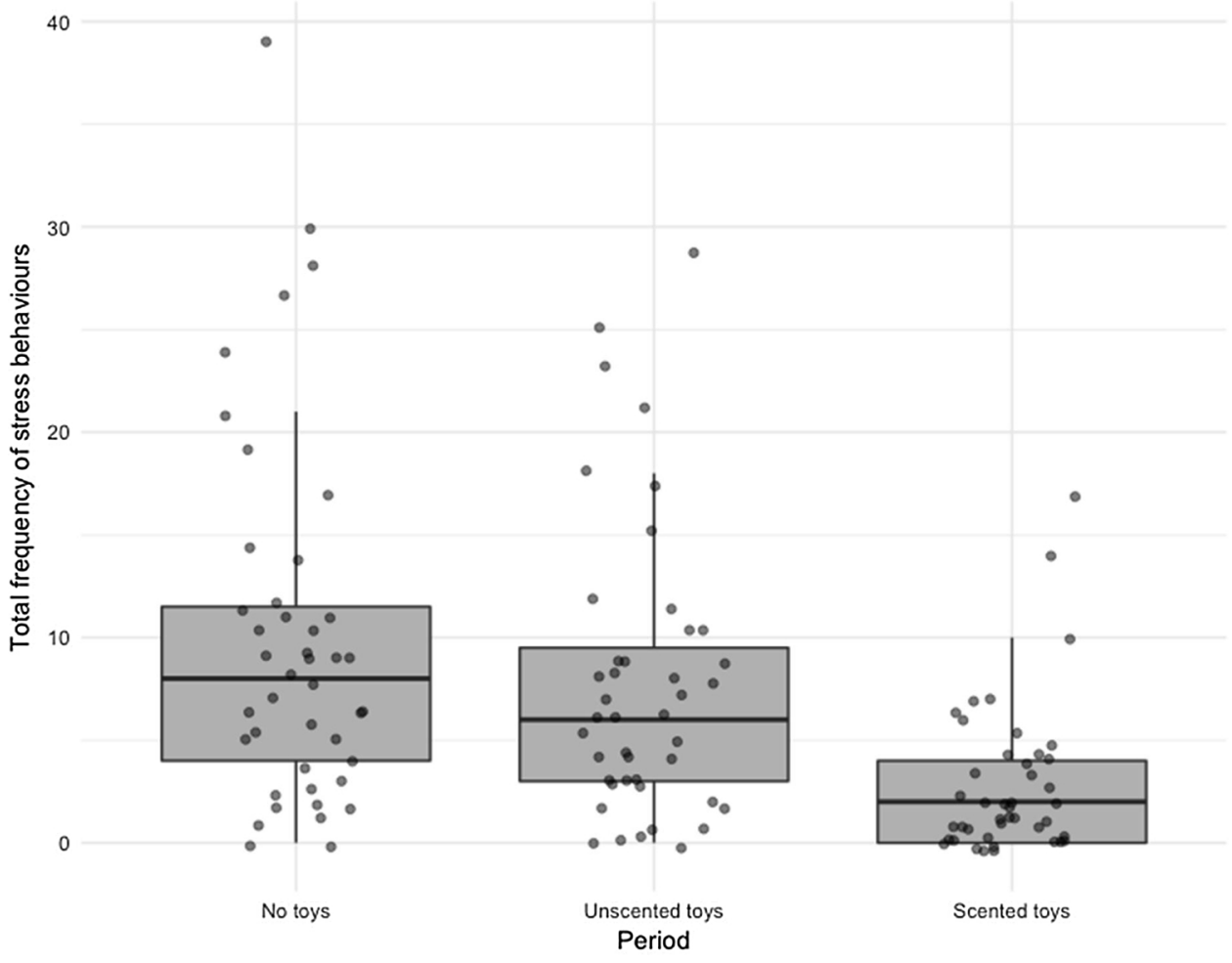

Fig. 2. Change in frequency of stress-related event behaviours across three different experimental periods. 
Table 4

Cross-tabs of one/zero on performing abnormal repetitive behaviours (ARBs), exploration behaviour, resting, and sleeping for no toys vs. unscented toys vs. scented toys.

\begin{tabular}{|c|c|c|c|c|c|c|c|c|}
\hline & \multicolumn{2}{|l|}{ ARBs } & \multicolumn{2}{|c|}{ Exploration } & \multicolumn{2}{|c|}{ Resting } & \multicolumn{2}{|c|}{ Sleeping } \\
\hline & None & Some & None & Some & None & Some & None & Some \\
\hline No toys (NT) & 13 & 31 & 12 & 31 & 18 & 26 & 29 & 15 \\
\hline Unscented toys $(\mathrm{T})$ & 15 & 29 & 11 & 32 & 18 & 26 & 34 & 10 \\
\hline Scented toys $(\mathrm{T}+)$ & 27 & 17 & 2 & 41 & 7 & 37 & 20 & 24 \\
\hline
\end{tabular}

significant difference in the likelihood of exploration when comparing NT with $\mathrm{T} / \mathrm{T}+$ periods combined $(\mathrm{z}=-2.27, \mathrm{p}=0.023)$ and $\mathrm{T}$ vs. $\mathrm{T}+$ periods $(\mathrm{z}=2.57, \mathrm{p}=0.010)$, likely down to increased chances of exploring during periods of scented toys (Table 4). Excluding samples where zero exploration was demonstrated revealed a significant effect of experimental period on the duration of exploration behaviour $\left(\chi^{2}(2)=33.31, \mathrm{p}<0.001\right.$; Fig. 4). Planned contrasts showed that there was a significant difference in time spent exploring when comparing periods of $\mathrm{NT}$ vs. $\mathrm{T} / \mathrm{T}+$ combined $(\mathrm{t}(62.5)=-4.00$, $\mathrm{p}<0.001)$ and when comparing $\mathrm{T}$ vs. $\mathrm{T}+$ periods $(\mathrm{t}(64.36)=5.21$, $\mathrm{p}<0.001)$.

\subsection{Resting}

There was a significant effect of period on the likelihood or not of demonstrating at least some resting behaviour $\left(\chi^{2}(2)=16.75\right.$, $\mathrm{p}<0.001$; Table 4). Planned contrasts revealed a significant difference in the likelihood of showing resting behaviour when comparing $\mathrm{T}+/ \mathrm{T}$ periods combined vs. NT $(\mathrm{z}=-2.15, \mathrm{p}=0.031)$ and the $\mathrm{T}$ vs. $\mathrm{T}+$ periods $(\mathrm{z}=3.03, \mathrm{p}=0.002)$. Excluding samples where zero resting was demonstrated revealed no significant effect of experimental period on the duration of resting behaviour $\left(\chi^{2}(2)=0.94, p=0.624\right)$.

\subsection{Sleeping}

There was a significant effect of period on the likelihood or not of demonstrating at least some sleeping behaviour $\left(\chi^{2}(2)=17.07\right.$, $\mathrm{p}<0.001$; Table 4). Planned contrasts revealed no significant difference in the likelihood of showing sleeping behaviour when comparing NT vs. $\mathrm{T} / \mathrm{T}+$ periods combined $(\mathrm{z}=-0.53, \mathrm{p}=0.599)$, but there was a significant difference in this likelihood when comparing $\mathrm{T}$ vs. $\mathrm{T}+$ periods $(\mathrm{z}=3.36, \mathrm{p}<0.001)$. Excluding samples where zero resting was demonstrated revealed no significant effect of time period on the duration of sleeping behaviour $\left(\chi^{2}(2)=4.02, p=0.13\right)$.

\subsection{Relationship between toy interaction and behaviours expressed}

Initial analyses confirmed that the $\mathrm{T}+$ phase altered the probability of interacting with toys and altered the probability of various welfarerelated behaviours being expressed. We followed up this analysis by attempting to establish whether the actual duration of interaction with toys was driving these effects, or whether in the absence of such an effect we might hypothesize that scent addition simply increased arousal in some way (which increased toy interaction as a by-product). A correlation analysis (using Kendall's tau) of time spent interacting with toys vs. duration for all other behaviours showed that the highest correlation coefficient was $|0.22|$ for the period with scented toys (all $\mathrm{p}>0.15$ ) and $|0.17|$ for the period with unscented toys (all $\mathrm{p}>0.26$ ) (periods were split due to non-independence of data). We also employed a GLMM approach, using the same null models as for the main analysis above, but also including or excluding toy interaction as a fixed factor. This revealed that there was no significant effect of whether dogs had interacted with a toy or not on their duration or likelihood of expressing the behaviours analysed in the main results section above (all $\mathrm{p}>0.17)$.

\section{Discussion}

Our results indicate that scent-enriched toys can, and do, affect the

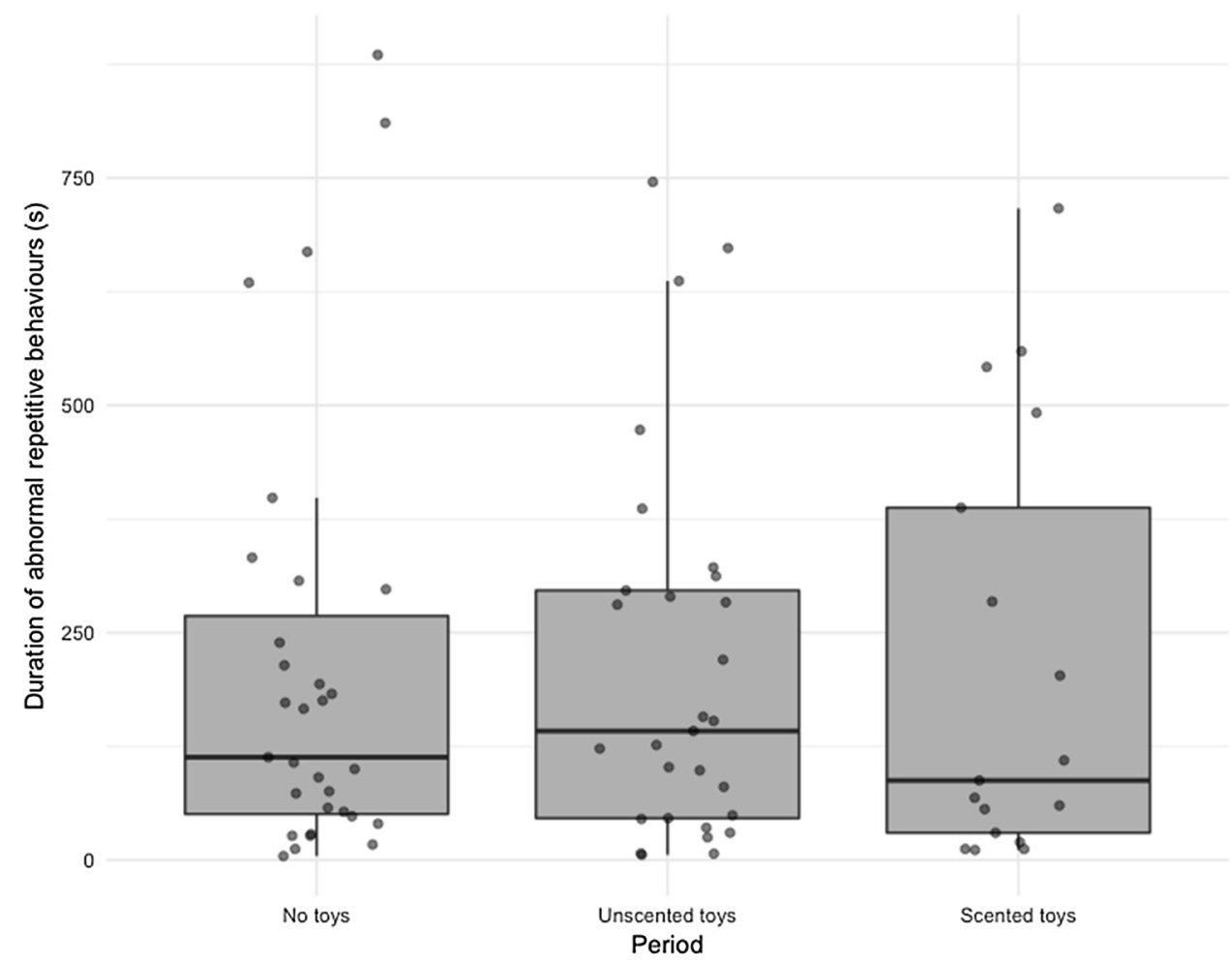

Fig. 3. Duration of performance of abnormal repetitive behaviours (ARBs) in seconds across the three experimental time periods. 


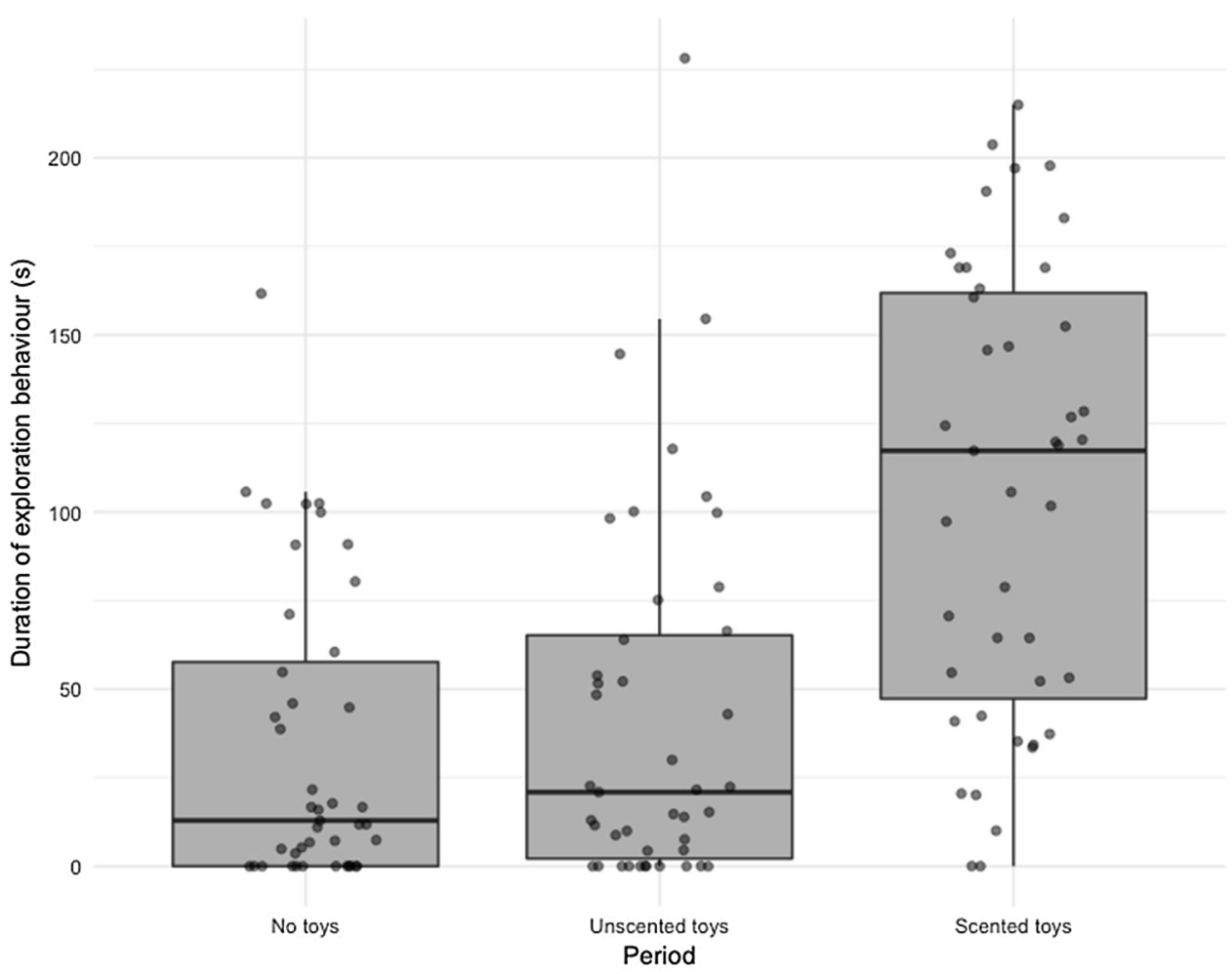

Fig. 4. Duration of exploration behaviour (s), excluding interaction with toys.

frequency and duration of welfare-indicative behaviours in kennels. When presented with scented toys dogs were more likely to play with them than during equivalent periods with unscented toys. Importantly, they were also more likely to play with the scented toys when presented with both scented and unscented toys simultaneously (during the $\mathrm{T}+$ condition). During periods of toy presentation the frequency of stress-related behaviours was reduced, even more so when the toys were scented. Abnormal Repetitive Behaviours (ARBs) were less likely to be expressed when toys were present and were expressed at a lower frequency again when toys were scented. However, the duration of ARBs was consistent across conditions, suggesting that toy play can distract dogs from commencing ARBs, but cannot impact on their motivation to do so once they've started performing them. The same pattern was observed for rest and sleep: dogs were more likely to perform them under toy presentation conditions, but they did not necessarily change how long they slept/rested for. Exploration behaviour was both more likely to occur in the presence of scented toys and lasted for longer in this condition. Finally, vocalisation behaviour was not affected by the presentation of toys, scented or otherwise.

Superficially, our results therefore look very promising, suggesting that adding scent to toys in rehoming kennels might (at least in the short-term) improve welfare outcomes. However, the follow-on analyses indicated that the mechanism by which this occurs is not necessarily directly causal. That is, the relationship between scented toy interaction and duration of behaviours indicative of improved welfare was weak, if not absent; dogs that interacted more with the toys when scented did not necessarily show the greatest improvements in welfarerelated behaviours. There is, however, still a relationship between the presence of the scent and the observed behavioural changes. This suggests that the scent enrichment may have a generalised effect: both encouraging more toy use for those that are motivated to do so, and generally enhancing positive welfare-related behaviour (explore, sleep) in those who are not toy-motivated, but might still gain from the novel stimulus.

The exact means by which scent enrichments work is still uncertain. There are three potential mechanisms: first, the scents may have a physiological effect. Blood tests following inhalation of essential oils show increased blood serum levels of compounds found therein, suggesting the potential for a pharmacological action (Kovar et al., 1987). However, Komori et al. (2006) found that diffusion of various oils prolonged or shortened sleep, but not in anosmic individuals. Secondly, scent enrichment may work due to neophilia, as seems to be the case where non-biologically relevant scents are used (Resende et al., 2011; Yu et al., 2009). Finally, evolutionary relevance of scents may trigger investigation and behavioural change (Wells and Egli, 2004).

In our study dogs showed no preference between the lavender- and rabbit-scented toy. This suggests that, unlike studies in non-canid species (e.g. Powell, 1995; Wells and Egli, 2004), the value of the scented toys was in their novelty and not in the evolutionary salience of the scent used. This chimes with other canine scent enrichment findings (e.g. Binks et al., 2018) and, if consistently found under replication, would be useful since it would support rehoming centres using a range of scents to maintain interest in toy enrichments. However, our findings are at odds with general research on enrichment which suggests that appetitive unconditioned stimuli are more effective at prolonging engagement and avoiding habituation (vs. novel stimuli) (Tarou and Bashaw, 2007). This being said, the assumption (that there is a connection between the scent of common prey species and the evolution of behavioural excitability) requires further exploration, in a range of species, to establish the degree to which such excitability might be a product of innate vs. learned responses.

The present study agrees with previous work that toys are little used by dogs in kennels (Wells, 2004a; Wells and Hepper, 2000). However, toy use was substantially increased from a median of $4 \mathrm{~s}$ in the unscented toys condition to $53 \mathrm{~s}$ in the scented toys condition (with the median for the actual scented toys being $89.5 \mathrm{~s}$ for lavender and $75.5 \mathrm{~s}$ for rabbit). A crucial factor for measuring enrichment success is level of engagement (Dawkins, 2004; Mellen and MacPhee, 2001). It has been suggested a critical aspect of welfare is whether the animal has the things it wants and the animals' preferences are of paramount importance (Dawkins, 2004, 2017). Making use of an item/device suggests doing so has value to the animal and having access to it improves 
welfare (Boissy et al., 2007; Dawkins, 2004; Yeates, 2016). The increase in interest in scented toys could show that such items have an increased value to dogs compared to unscented toys. However, it is important not focus too much on a 'giving animals what they want' measure of welfare. Aspects that bring an animal pleasure in the short term may not be what are best for their long-term welfare (Yeates, 2016). For example, dogs may select a more salient, stimulating scent but the increase in arousal may increase their reactivity. Conversely, a 'relaxing' scent, while having less of an impact on immediate welfare, may improve the animal's ability to cope long term. More research into the behavioural effects of different scents in the long term is needed.

Our behavioural data suggest having scented toys in the kennel may alter behaviour in a way that is consistent with improved welfare, which may in turn increase the chances of adoption. The addition of scent to toys encouraged their use but also encouraged exploration behaviour, reduced the occurrence of stress-related behaviours and ARBs and made sleep and rest more likely. Our study builds on the work of Graham et al. (2005b) by showing that dogs will choose to interact with scented items when given the choice, but importantly shows that the scent may have 'spill-over' effects, generally encouraging more kennel exploration and reducing stress-related behaviours. Control over the environment is an important part of animal welfare (Boissy et al., 2007). For this reason any enrichment should be able to be avoided by the animal concerned, this is an issue within olfactory enrichment as scents can permeate the whole environment (Wells, 2009). Scented toys offer three advantages over the diffused scents used by Graham et al. (2005b) (though see Binks et al., 2018): (a) they give the dog an option of whether to interact with the enrichment or not, (b) they avoid the risk of frustration occurring at not being able to investigate the source of the scent (Yeates, 2016), and (c) they can be tailored to each dog. All dogs react differently to kennels (Hiby et al., 2006; Rooney et al., 2007) and their behaviour changes over time (Hiby et al., 2006; Rooney et al., 2007; Wells and Hepper, 1992). Scents can have a relaxing (Shaw et al., 2007) or stimulating (Lim et al., 2005) effect. Olfactory enrichment studies in other species have been successful for a variety of needs such as increasing activity (Wells and Egli, 2004) and decreasing stereotypy (Resende et al., 2011). Scented toys are an enrichment tool that allows kennel workers to select a scent type which will have the desired effect for a particular dog's current needs.

Although adoption success was not directly measured in this study previous research has shown people prefer to adopt dogs that are playful and quiet (Holland, 2019; Protopopova and Wynne, 2014; Wells and Hepper, 1992, 2000), both behaviours that were encouraged by scented toys. Conversely, scented toys also led to an increased likelihood of sleeping which people find unattractive (Wells and Hepper, 2000). Generally people prefer to adopt dogs which interact with them (Protopopova and Wynne, 2014) and there is evidence olfactory enrichment can increase positive social behaviour in other species, though this has not been tested in canids (Powell, 1995; Rafacz and Santymire, 2014). Furthermore, people show a preference for dogs at the front of their kennel. Moving a dog's bed to the front of the kennel encouraged them to spend more time there (Wells and Hepper, 2000) and it is possible a scented toy fixed to the kennel front would do the same. However, moving the bed meant dogs used it less (Wells and Hepper, 2000) and dogs seem to prefer toys loose on the floor (Pullen et al., 2010). The impact of scent enrichment (particularly when paired with toys) on behaviours related to adoption success requires further study.

One of the most common problems with enrichment is habituation (Tarou and Bashaw, 2007). Research on zoo-housed felids suggests the positive effect of scent enrichment wanes over time (Wells and Egli, 2004; Yu et al., 2009). However, this effect may be mitigated by changing the scent being used (Gronqvist et al., 2013) as olfactory enrichment has shown to be the least liable to habituation in dogs (Bowman et al., 2015; Graham et al., 2005a; Wells, 2006). Pullen et al. (2010) found that dogs habituated to toys upon repeated presentation, but dishabituation could be achieved by presenting the same toy with the addition of an olfactory cue (saliva from a previous play session). Likewise, it is probable that habituation to scented toys could be prevented by the addition of a new scent at regular intervals. Future research should test this hypothesis.

There are some clear limitations of using rehoming shelter dogs: their origin and experiences are often unknown. Most importantly, their prior experience with the toys or scents could not have been established. However, though prior experience can introduce bias, the use of a within-subject design should have diminished any such effects. Furthermore, prior experience with either toys or scents would have reduced the difference between baseline and the other conditions, making a false positive result less likely. Finally, conducting the study in the 'field' improves the viability of the practical application of the results as the aim was to increase the enrichment value of toys currently used by rehoming centres. The current study only looked at a brief period of time because the average length of stay was seven days or fewer. As such it was unable to account for the daily and longitudinal fluctuations in behaviour, which have previously been noted (Hiby et al., 2006; Rooney et al., 2007; Wells and Hepper, 1992).

In a working shelter it is not possible to entirely remove scent traces from the environment. This means that residual scent likely remained. However, every effort was taken to ensure that the toys remained free from scent contamination. This being said, previous studies have reasoned that even with perfect toy hygiene, scent enrichments will diffuse across multiple kennels. Other studies have therefore chosen to treat subjects as 'blocks' and have eschewed counterbalancing (reasoning that once a scent enrichment had been used in a kennel any adjacent dogs had also been exposed to it) (Graham et al., 2005a, 2005b; Binks et al., 2018).

Unlike many in-shelter studies, the current work was able to ensure that all trials were carried out when the centre was closed to the public, as differing visitor presence is likely to affect dogs' behaviour (Hewison et al., 2014) and is often a confounding factor in shelter-based work.

\section{Conclusion}

Finding an enrichment strategy that is practical for use in a busy rehoming shelter is an ongoing problem. This study suggests that scented toys have the potential to be an additional tool in the suite of enrichment practices. The addition of scented toys not only increased toy usage but caused behavioural changes which, over time, may be indicative of improved wellbeing. The effects seen were not significantly affected by the type of scent used, suggesting the value of scented toys may lie in their novelty and not their biological salience. Overall, results indicated that dogs in rescue kennels may benefit if commonly used toys have scents applied. Habituation to toys may be avoidable if new scents are used periodically. Further research is required to explore the findings presented in this paper, particularly the lack of relationship between interaction with enrichment and behavioural improvements. Using a range of scents with varying levels of perceived salience and exploring long-term behavioural changes and adoptability may be beneficial.

\section{Data statement}

To ensure open and transparent peer review of our methods we have included our dataset and analysis code (in R) at the following online location: https://doi.org/10.5281/zenodo.2641955. The latter is annotated to aid understanding of the analysis undertaken.

\section{Declaration of Competing Interest}

None. 


\section{Acknowledgements}

The authors would like to thank the Dogs Trust veterinary and behaviourist teams for approving the project and the team at Dogs Trust Darlington for accommodating the research, with special thanks to Lauren Sutcliffe, James Bannister, Niki Holroyd and Francesca Gent for their help and support. We would also like to thank two anonymous reviewers for their helpful comments and suggestions.

\section{References}

Association of Dogs and Cats Homes, 2015. Code of Practice. Retrieved from. http:// www.adch.org.uk/abouTadch.

Bates, D., Maechler, M., Bolker, B., Walker, S., 2015. Fitting linear mixed-effects models using lme4. J. Stat. Soft. 67 (1), 1-48. https://doi.org/10.18637/jss.v067.i01.

Beerda, B., Schilder, M., Van Hooff, J., De Vries, H.W., 1997. Manifestations of chronic and acute stress in dogs. Appl. Anim. Behav. Sci. 52 (3), 307-319.

Beerda, B., Schilder, M.B., Van Hooff, J., De Vries, H.W., Mol, J.A., 1998. Behavioural, saliva cortisol and heart rate responses to different types of stimuli in dogs. Appl. Anim. Behav. Sci. 58 (3), 365-381.

Beerda, B., Schilder, M.B.H., Van Hooff, J., De Vries, H.W., Mol, J.A., 1999. Chronic stress in dogs subjected to social and spatial restriction. I. Behavioural Responses. Physiol. Behav. 66 (2), 233-242.

Beerda, B., Schilder, M.B.H., Van Hooff, J., De Vries, H.W., Mol, J.A., 2000. Behavioural and hormonal indicators of enduring environmental stress in dogs. Anim. Welf. 9 (1), 49-62.

Binks, J., Taylor, S., Wills, A., Montrose, V.T., 2018. The behavioural effects of olfactory stimulation on dogs at a rescue centre. Appl. Anim. Behav. Sci. 202, 69-76.

Boissy, A., Manteuffel, G., Jensen, M.B., Moe, R.O., Spruijt, B., Keeling, L.J., Winckler, C., Forkman, B., Dimitrov, I., Langbein, J., Bakken, M., 2007. Assessment of positive emotions in animals to improve their welfare. Physiol. Behav. 92 (3), 375-397.

Bowman, A., Scottish, S.P.C.A., Dowell, F.J., Evans, N.P., 2015. 'Four Seasons' in an animal rescue centre; classical music reduces environmental stress in kennelled dogs. Physiol. Behav. 143, 70-82.

Cafazzo, S., Maragliano, L., Bonanni, R., Scholl, F., Guarducci, M., Scarcella, R., Di Paolo, M., Pontier, D., Lai, O., Carlevaro, F., Bucci, E., 2014. Behavioural and physiological indicators of shelter dogs' welfare: Reflections on the no-kill policy on free-ranging dogs in Italy revisited on the basis of 15 years of implementation. Physiol. Behav. 133, 223-229.

Conley, M.J., Fisher, A.D., Hemsworth, P.H., 2014. Effects of human contact and toys on the fear responses to humans of shelter-housed dogs. Appl. Anim. Behav. Sci. 156, $62-69$.

Coppola, C.L., Grandin, T., Enns, R.M., 2006. Human interaction and cortisol: can human contact reduce stress for shelter dogs? Physiol. Behav. 87 (3), 537-541.

Cornu, J.N., Cancel-Tassin, G., Ondet, V., Girardet, C., Cussenot, O., 2011. Olfactory detection of prostate cancer by dogs sniffing urine: a step forward in early diagnosis. Eur. Urol. 59 (2), 197-201.

Dawkins, M.S., 2004. Using behaviour to assess animal welfare. Anim. Welf. 13, 3-7.

Dawkins, M.S., 2017. Animal welfare with and without consciousness. J. Zool. 301 (1), $1-10$.

Döring, D., Haberland, B.E., Bauer, A., Dobenecker, B., Hack, R., Schmidt, J., Erhard, M.H., 2016a. Behavioural observations in dogs in 4 research facilities: do they use their enrichment? J. Vet. Behav, 13, 55-62.

Döring, D., Ketter, D.A., Klima, A., Küchenhoff, H., Dobenecker, B., Schmidt, J., Erhard, M.H., 2016b. Horn of calf hooves as chews in laboratory dogs. J. Vet. Behav. 13 39-45.

Goodwin, K.M., Engel, R.E., Weaver, D.K., 2010. Trained dogs outperform human surveyors in the detection of rare spotted knapweed (Centaurea stoebe). Invasive Plant Sci. Manag. 3 (2), 113-121.

Graham, L., Wells, D.L., Hepper, P.G., 2005a. The influence of visual stimulation on the behaviour of dogs housed in a rescue shelter. Anim. Welf. 14 (2), 143-148.

Graham, L., Wells, D.L., Hepper, P.G., 2005b. The influence of olfactory stimulation on the behaviour of dogs housed in a rescue shelter. Appl. Anim. Behav. Sci. 91 (1), 143-153.

Gronqvist, G., Kingston-Jones, M., May, A., Lehmann, J., 2013. The effects of three types of environmental enrichment on the behaviour of captive Javan gibbons (Hylobates moloch). Appl. Anim. Behav. Sci. 147 (1), 214-223.

Hennessy, M.B., Davis, H.N., Williams, M.T., Mellott, C., Douglas, C.W., 1997. Plasma cortisol levels of dogs at a county animal shelter. Physiol. Behav. 62 (3), 485-490.

Hennessy, M.B., Voith, V.L., Young, T.L., Hawke, J.L., Centrone, J., McDowell, A.L., Davenport, G.M., 2002. Exploring human interaction and diet effects on the behaviour of dogs in a public animal shelter. J. Appl. Anim. Welf. Sci. 5 (4), 253-273.

Hermiston, C., Montrose, V.T., Taylor, S., 2018. The effects of dog-appeasing pheromone spray upon canine vocalizations and stress-related behaviours in a rescue shelter. J. Vet. Behav. 26, 11-16.

Herron, M.E., Kirby-Madden, T.M., Lord, L.K., 2014. Effects of environmental enrichment on the behaviour of shelter dogs. J. Am. Vet. Med. Assoc. 244 (6), 687-692.

Hetts, S., Clark, J.D., Calpin, J.P., Arnold, C.E., Mateo, J.M., 1992. Influence of housing conditions on beagle behaviour. Appl. Anim. Behav. Sci. 34 (1-2), 137-155.

Hewison, L.F., Wright, H.F., Zulch, H.E., Ellis, S.L., 2014. Short term consequences of preventing visitor access to kennels on noise and the behaviour and physiology of dogs housed in a rescue shelter. Physiol. Behav. 133, 1-7.
Hiby, E.F., Rooney, N.J., Bradshaw, J.W., 2006. Behavioural and physiological responses of dogs entering re-homing kennels. Physiol. Behav. 89 (3), 385-391.

Hoffman, C.L., Workman, M.K., Roberts, N., Handley, S., 2017. Dogs' responses to visual, auditory, and olfactory cat-related cues. Appl. Anim. Behav. Sci. 188, 50-58.

Holland, K.E., 2019. Acquiring a pet dog: a review of factors affecting the decisionmaking of prospective dog owners. Animals 9, 124.

Hubrecht, R.C., 1993. A comparison of social and environmental enrichment methods for laboratory housed dogs. Appl. Anim. Behav. Sci. 37, 345-361.

Hubrecht, R.C., Serpell, J.A., Poole, T.B., 1992. Correlates of pen size and housing conditions on the behaviour of kennelled dogs. Appl. Anim. Behav. Sci. 34 (4), 365-383.

Kiddie, J.L., Collins, L.M., 2014. Development and validation of a quality of life assessment tool for use in kennelled dogs (Canis familiaris). Appl. Anim. Behav. Sci. 158, $57-68$.

Komori, T., Matsumoto, T., Motomura, E., Shiroyama, T., 2006. The sleep-enhancing effect of valerian inhalation and sleep-shortening effect of lemon inhalation. Chem. Senses 31 (8), 731-737.

Koolhaas, J.M., Bartolomucci, A., Buwalda, B., de Boer, S.F., Flügge, G., Korte, S.M., Meerlo, P., Murison, R., Olivier, B., Palanza, P., Richter-Levin, G., Sgoifo, A., Steimer, T., Stiedl, O., van Dijk, G., Wöhr, M., Fuchs, E., 2011. Stress revisited: a critical evaluation of the stress concept. Neurosci. Biobehav. Rev. 35 (5), 1291-1301.

Kovar, K.A., Gropper, B., Friess, D., Ammon, H.P.T., 1987. Blood levels of 1, 8-Cineole and locomotor activity of mice after inhalation and oral administration of rosemary Oil1. Planta Med. 53 (4), 315-318.

Kuznetsova, A., Brockhoff, P.B., Christensen, R.H.B., 2017. lmerTest package: tests in linear mixed effects models. J Stat. Soft. 82 (13), 1-26. https://doi.org/10.18637/jss. v082.i13.

Lim, W.C., Seo, J.M., Lee, C.I., Pyo, H.B., Lee, B.C., 2005. Stimulative and sedative effects of essential oils upon inhalation in mice. Arch. Pharm. Res. 28 (7), 770-774.

Mellen, J., MacPhee, M., 2001. Philosophy of environmental enrichment: past, present, and future. Zoo Biol. 20 (3), 211-226.

Mullahy, J., 1986. Specification and testing of some modified count data models. J. Economet. 3, 341-365.

Normando, S., Corain, L., Salvadoretti, M., Meers, L., Valsecchi, P., 2009. Effects of an enhanced human interaction program on shelter dogs' behaviour analyzed using a novel nonparametric test. Appl. Anim. Behav. Sci. 116 (2), 211-219.

Owczarczak-Garstecka, S.C., Burman, O.H.P., 2016. Can sleep and resting behaviours be used as indicators of welfare in shelter dogs (Canis lupus familiaris)? PLoS One 11 (10), e0163620.

Part, C.E., Kiddie, J.L., Hayes, W.A., Mills, D.S., Neville, R.F., Morton, D.B., Collins, L.M., 2014. Physiological, physical and behavioural changes in dogs when kennelled: testing the validity of stress parameters. Physiol. Behav. 133, 260-271.

Powell, D.M., 1995. Preliminary evaluation of environmental enrichment techniques for African lions. Anim. Welf. 4, 361-370.

Pullen, A.J., Merrill, R.J.N., Bradshaw, J.W.S., 2010. Preferences for toy types and presentations in kennel housed dogs. Appl. Anim. Behav. Sci. 125 (3), 151-156.

Price, L.J., 2010. A preliminary study of the effects of environmental enrichment on the behaviour of captive African wild dogs (Lycaon pictus). Biosci. Horiz. 3 (2), 132-140.

Protopopova, A., Wynne, C.D.L., 2014. Adopter-dog interactions at the shelter: behavioural and contextual predictors of adoption. Appl. Anim. Behav. Sci. 157, 109-116.

R Core Team, 2016. R: a Language and Environment for Statistical Computing. URL. R Foundation for Statistical Computing, Vienna, Austria. https://www.R-project.org/.

Rafacz, M.L., Santymire, R.M., 2014. Using odor cues to elicit a behavioural and hormonal response in zoo-housed African wild dogs. Zoo Biol. 33 (2), 144-149.

Resende, L.D., Gomes, P.K.C., Andriolo, A., Genaro, G., Remy, G.L., Ramos, A.V.D., 2011. Influence of cinnamon and catnip on the stereotypical pacing of Oncilla Cats (Leopardus tigrinus) in captivity. J. Appl. Anim. Welf. Sci. 14 (3), 247-254.

Revelle, W., 2018. psych: Procedures for Personality and Psychological Research. Northwestern University, Evanston, Illinois, USA https://CRAN.R-project.org/ package $=$ psych Version $=1.8 .4$.

Rooney, N.J., Gaines, S.A., Bradshaw, J.W., 2007. Behavioural and glucocorticoid responses of dogs (Canis familiaris) to kennelling: investigating mitigation of stress by prior habituation. Physiol. Behav. 92 (5), 847-854.

Royal Society for the Prevention of Cruelty to Animals, 2015. The Welfare of Seized Dogs in Kennels a Guide to Good Practice. Retrieved from. http://politicalanimal.org.uk/ topics/wales/welfare-seized-dogs-kennels/.

Schipper, L.L., Vinke, C.M., Schilder, M.B., Spruijt, B.M., 2008. The effect of feeding enrichment toys on the behaviour of kennelled dogs (Canis familiaris). Appl. Anim. Behav. Sci. 114 (1), 182-195.

Shaw, D., Annett, J.M., Doherty, B., Leslie, J.C., 2007. Anxiolytic effects of lavender oil inhalation on open-field behaviour in rats. Phytomed. 14 (9), 613-620.

Stavisky, J., Brennan, M.L., Downes, M., Dean, R., 2012. Demographics and economic burden of un-owned cats and dogs in the UK: results of a 2010 census. BMC Vet. Res. 8 (1), 1-9.

Tarou, L.R., Bashaw, M.J., 2007. Maximizing the effectiveness of environmental enrichment: suggestions from the experimental analysis of behaviour. Appl. Anim. Behav. Sci. 102, 189-204.

Taylor, K.D., Mills, D.S., 2007. The effect of the kennel environment on canine welfare: critical review of experimental studies. Anim. Welf. 16, 435-447.

Walker, J.K., Dale, A.R., D'Eath, R.B., Wemelsfelder, F., 2009. Welfare assessment in dogs: reducing the invasiveness of welfare assessment methodology through trial and validation of a qualitative, behavioural based approach. J. Vet. Behav. 4 (2), 102-103.

Wells, D.L., 2004a. The influence of toys on the behaviour and welfare of kennelled dogs. Anim. Welf. 13 (3), 367-373.

Wells, D.L., 2004b. A review of environmental enrichment for kennelled dogs, Canis familiaris. Appl. Anim. Behav. Sci. 85, 307-317.

Wells, D.L., 2006. Aromatherapy for travel-induced excitement in dogs. J. Am. Vet. Med. 
Assoc. 229 (6), 964-967.

Wells, D.L., 2009. Sensory stimulation as environmental enrichment for captive animals: a review. Appl. Anim. Behav. Sci. 118 (1), 1-11.

Wells, D.L., Egli, J.M., 2004. The influence of olfactory enrichment on the behaviour of captive black-footed cats, Felis nigripes. Appl. Anim. Behav. Sci. 85 (1), 107-119.

Wells, D.L., Hepper, P.G., 1992. The behaviour of dogs in a rescue shelter. Anim. Welf. 1 (3), 171-186.
Wells, D.L., Hepper, P.G., 2000. The influence of environmental change on the behaviour of sheltered dogs. Appl. Anim. Behav. Sci. 68 (2), 151-162.

Yeates, J., 2016. Quality of life and animal behaviour. Appl. Anim. Behav. Sci. 181, 19-26.

Yu, S., Jiang, Z., Zhu, H., Li, C., Zhang, E., Zhang, J.X., Harrington, C., 2009. Effects of odors on behaviours of captive Amur leopards Panthera pardus orientalis. Curr. Zool. 55 (1), 20-27. 